\title{
Conversation Skills in Chinese-Speaking Preschoolers with Autism: The Contributing Role of Parents' Verbal Responsiveness
}

\author{
Wing Chee So ( $\nabla$ wingchee@cuhk.edu.hk) \\ Chinese University of Hong Kong Faculty of Education https://orcid.org/0000-0002-6538-1663 \\ Xueke Song \\ Chinese University of Hong Kong School of Education: The Chinese University of Hong Kong Faculty of Education \\ Chun Ho Cheng \\ Chinese University of Hong Kong School of Education: The Chinese University of Hong Kong Faculty of Education \\ Wing Wun Law \\ Chinese University of Hong Kong School of Education: The Chinese University of Hong Kong Faculty of Education \\ Tiffany Wong \\ Chinese University of Hong Kong School of Education: The Chinese University of Hong Kong Faculty of Education \\ Oi Ki Leung \\ Chinese University of Hong Kong School of Education: The Chinese University of Hong Kong Faculty of Education \\ Ying Huang \\ Chinese University of Hong Kong School of Education: The Chinese University of Hong Kong Faculty of Education
}

Research

Keywords: conversation abilities, parental inputs, intervention, naturalistic language sampling, Chinese-speaking

Posted Date: January 28th, 2021

DOI: https://doi.org/10.21203/rs.3.rs-154429/v1

License: (c) (i) This work is licensed under a Creative Commons Attribution 4.0 International License. Read Full License

Version of Record: A version of this preprint was published at Journal of Autism and Developmental Disorders on April 23rd, 2021. See the published version at https://doi.org/10.1007/s10803-021-05017-5. 


\section{Abstract}

Background: Children with autism spectrum disorder (ASD) have deficits in conversation skills, yet the growth of conversation abilities is understudied, especially in Chinese-speaking populations, whose autism rates are rising. Additionally, little is known about whether parents' verbal responsiveness (utterances that follow the child's focus of attention, actions, and communications) and redirectives (utterances that require the child to change the focus of attention) are related to their ASD children's elicitation of responses in a conversation. This study had two aims: 1) documenting the growth of conversation skills in Chinese-speaking preschool children with autism; 2) investigating the association between parents' verbal responsiveness and redirectives and the production of appropriate responses in the children with ASD and the number of conversational turns in the parent-child dyads.

Method: Participants were taken from a larger intervention project for (Cantonese) Chinese-speaking individuals with ASD. Thirty-seven participants with ASD (32 males), average age five to six years, and their parents, contributed their language samples. These children interacted with their parents at four time points over nine months. Each time, the parents and children played with a standard set of toys for 20 minutes. The severity of autism, cognitive functioning, and language abilities of the children were assessed before the collection of their language samples.

Results: Our findings showed that the number of conversational turns and the proportion of child-initiated conversation (but not the proportion of children's appropriate responses) grew over the course of nine months. After controlling for time, autism severity, and language skills, parents' verbal responsiveness positively predicted children's appropriate responses. Parents' redirectives negatively predicted the proportion of children's appropriate responses and the number of conversational turns.

Limitations: Our language samples were collected from 37 children aged four to eight years. Even though they were followed at four time points, this is too small a sample and heterogeneity of language abilities is not observed along the lifespan in individuals with autism.

Conclusions: Some but not all aspects of conversation skills grew over nine months in Chinese-speaking children with ASD. Parents' verbal responsiveness was positively related to the children's elicitation of appropriate responses.

\section{Background}

Autism spectrum disorder (ASD) is widely recognized as a complex, heterogeneous neurodevelopmental condition that affects about one in 54 individuals (Center for Disease Control, 2020). According to the 5th edition of the Diagnostic and Statistical Manual of Mental Disorders (DSM-5; American Psychological Association; 2013), individuals with ASD have impairments in social communication and interaction, and they produce restricted and repetitive behaviors. Regarding social interaction, impairments in pragmatic speech appear across different language levels and ages along the autism spectrum (e.g., Baird \& Borbury, 2016; Lam \& Yeung, 2012; Tager-Flusberg et al., 2005; Volden et al., 2009). The present study focuses on the pragmatic speech produced during conversation. Conversational interactions require a range of pragmatic skills such as turn-taking, topic initiation, and topic maintenance (Ninio \& Snow, 1996; Wetherby, 2006).

Previous research has reported deficits in conversational turn-taking and maintaining topics during conversation in children with ASD who were verbal (Landa et al., 1992; Tager-Flusberg \& Anderson, 1991). Specifically, compared to children without ASD, these children were found to have difficulties in expanding conversational topics, maintaining appropriate and relevant topics, and engaging in turn-taking, thus resulting in little reciprocal conversation (BaumingerZviely \& Agam-Ben-Artzi, 2014; Capps, Kehres, \& Sigman, 1998; Jones \& Schwartz, 2009; Lam \& Yeung, 2012; Losh \& Capps, 2003). These deficits persist when these children become adolescents (e.g., Adams, Green, Gilchrist, \& Cox, 2002; Koning \& Magill-Evans, 2001; Paul, Orlovski, Marcinko, \& Volkmar, 2009; Philofsky, Fidler, \& Hepburn, 2007). Of these studies, Paul et al. (2009) identified three major pragmatic difficulties: topic management, quantity and type of information provided, and reciprocity.

However, the development of conversation skills is understudied and the findings to date are inconclusive. In one of the few studies undertaken, Hale and Tager-Flusberg (2005) tested 57 children with high-functioning ASD (average IQ $=77$ ) at two time points over a year, observing conversations with their parents. These children were found to have made significant improvement in their ability to maintain a topic of discourse and to present a significant reduction in imitation of their parents' speech. In a recent study by DiStefano, Shih, Kaiser, Landa, and Kasari (2016), 55 children with low-functioning ASD and minimal verbal skills participated in an intervention program in one of two joint engagement-based intervention conditions. Children in both conditions showed improvement in the length and frequency of their communication interchanges over the course of the intervention. On the contrary, Tager-Flusberg and Anderson (1991) found that children diagnosed with ASD did not show any developmental change in discourse ability over a year. However, only six children participated in their study. Given the heterogeneity of language abilities in autism, it is difficult to detect developmental change in such a small group of children.

Besides the inconclusive findings on the developmental changes of conversation skills, the aforementioned studies focused on English-speaking children with autism and none of them examined the conversational skills of Chinese-speaking children with autism or documented the growth of these skills over time. According to the Education Bureau in Hong Kong, the number of students recently diagnosed with ASD was 7,200 in 2015/16, 8,600 in 2016/17, and 10,300 in $2017 / 18$, representing a $20 \%$ rise each year. With such a large number of young children diagnosed with ASD, it is crucial to understand their language and communication impairments, particularly deficits in conversation.

As a result, the first objective of the present study was to document the growth of conversational skills in Chinese-speaking preschool children with autism over nine months at four time points. Changes were modeled over time. In this study, we collected naturalistic language samples from parent-child dyads. Naturalistic language samples carry detailed language information regarding children's initiation of conversation, appropriate responses to the parents, and their maintenance of conversation (DiStefano et al., 2016). 
Parents provide "around the clock" intervention for children with autism (Koegel, Koegel, Frea, \& Smith, 1995), even though many receive regular interventions from outside the family. Therefore, besides characterizing the conversational skills of Chinese-speaking children with autism over time, we investigated whether parents' verbal responsiveness and redirectives in a conversation would elicit children's appropriate responses and then increase the number of conversation turns. Parents' verbal responsiveness refers to the utterances that follow the child's focus of attention, actions, and communications (Yoder \& Warren, 1999; Landry et al., 2000; Siller \& Sigman, 2002; McDuffie \& Yoder, 2010). Parents' redirectives refer to the utterances that require the child to stop attending to the event, object, or person with which they are engaged and attend to something else (McCathren, Yoder, \& Warren, 1995).

Since the 70s and 80 s, researchers have suggested parents or therapists adopt a child-oriented or scaffolded approach when interacting with children with developmental disabilities (Bruner, 1978; Nelson, 1989). Under this approach, parents should follow the child's lead, respond to, and expand or recast the child's initiations while keeping the meaning of the child's utterances in order to foster their children's verbal participation. Previous findings have shown that children with developmental delay or developmental disabilities are more likely to converse on the topics that were continued by their parents on the immediately preceding topic of children's interests than the topics initiated by the parents (Yoder \& Davies, 1990; Yoder, Davies, \& Bishop, 1992). Besides expansion and recast, questions asked by parents may elicit children's continuations too. In an experiment conducted by Yoder and colleagues, an adult experimenter interacted with children with developmental delay using two different styles - topic-continuing wh-questions and topic-continuing comments (Yoder, Davies, Bishop, \& Munson, 1994). Their findings showed that topic-continuing wh-questions are more likely than comments to elicit child continuations.

Adults' or parents' verbal responsiveness can elicit further children conversation for a few reasons. First, the child may be interested in maintaining an interaction about a topic they had previously shown interest in (Olsen-Fulero \& Conforti, 1983). Based on this view, the child is more likely to maintain an established topic when confronted with an adult utterance that maintains the child's topic than when the adult initiates a new topic. Second, it may be easier for the child to understand adult speech that continues the established topics and attentional lead, which results in less information processing load (Bloom, Rocissano, \& Hood, 1976; Landry \& Chapieski, 1989).

However, the aforementioned studies, which investigated the influence of parents' verbal responsiveness on children's participation in a conversation, only examined children with developmental delays (especially those with Down Syndrome). To date, no study has examined children with ASD. Nevertheless, it is crucial to understand whether parents' verbal responsiveness would facilitate the elicitation of appropriate responses in these children who are found to show deficits in responding to their parents in a conversation. If so, therapists can recommend scaffolding strategies for developing conversation skills to parents of children with ASD.

Having said that, a few studies have reported that parents' verbal responsiveness facilitates their children's play behaviors and joint attention. A study by Bottema-Beutel and colleagues examined 98 parent-child dyads (Bottema-Beutel et al., 2018a) of which 50 were young children with ASD and their parents, and 48 were toddlers with typical development and their parents, with the children in both groups having a mental age of 13 months. Their study found that child toy play was more likely to elicit follow-in utterances (utterances that relate to the child's attentional focus) from the parents of children with ASD than from those of children with typical development. In turn, these follow-in utterances had a facilitative effect on the functional play of children with ASD, whereas caregiver-focused utterances had an inhibitory effect. A later study by Bottema-Beutel and colleagues also found that parents' follow-in utterances elicited supported joint engagement in both young children with ASD and typical development, with strong association in children with ASD (Bottema-Beutel, Lloyd, Watson, \& Yoder, 2018b). In contrast with follow-in utterances, redirectives are negatively related to joint attention as the child is required to shift the focus of attention and follow the adult's need in order to establish joint attention with the adult (Landry \& Chapiesky, 1989).

Abundant research also reported the positive influence of parents' verbal responsiveness on language development in children with ASD (e.g., Bottema-Beutel, Yoder, Hochman, \& Watson, 2014; Dimitrova, Özçalıskan, \& Adamson, 2015; McDuffie \& Yoder, 2010; Haebig et al., 2013; see reviews in Edmunds, Kover, \& Stone, 2019). McDuffie and Yoder (2010) categorized verbal responsiveness into follow-in comments ('utterances that follow the child's focus of attention and describe what the child is looking at or playing with, without conveying the expectation that the child do something different or respond verbally to the parent') and follow-in directives ('utterances that follow the child's current focus of attention and convey a request for the child to change some aspect of his/her play with toys or to provide a verbal response') (p. 1032). In their study, they followed preschoolers with autism over six months and measured the vocabulary they produced in play episodes at two time points. They found that parent follow-in comments and follow-in directives at baseline significantly predicted children's vocabulary use six months later. Similarly, Haebig, McDuffie, and Weismer (2013a, 2013b) found that follow-in directives are positively associated with language comprehension and production a year later in children who were minimally verbal or verbally fluent, while follow-in comments have the same facilitating effect only in children who were minimally verbal. Siller and Sigman $(2002,2008)$ even found that follow-in comments could predict gains in language skills 10 and 16 years later in children with autism. In contrast with follow-in comments or directives, relatively less is known about how parents redirectives influence language development in children with ASD. Besides, the relationship between redirectives and language development for typically developing children and children with developmental delays is either negative or non-significant (Crawley \& Spiker, 1983; Harris, 1994; Tomasello \& Farrar, 1986).

Taken together, previous research has shown parents' verbal responsiveness has positive impact on the elicitation of contingent play and joint attention behaviors and even on long-term language development in children with ASD. However, no study to date has examined the influence of parents' verbal responsiveness and redirectives in these children's participation in a conversation. Specifically, would children with ASD be more likely to elicit appropriate responses under parents' verbal responsiveness than under parents' redirectives? The second objective of the present study addressed this question. Based on the findings of the previous studies that showed the positive influence of parents' verbal responsiveness in children's behaviors and language skills, we hypothesized that parents' verbal responsiveness would positively predict the proportion of appropriate responses from their children and hence the number of conversational turns. In contrast, redirectives would negatively predict appropriate responses and conversational turns in their children. 


\section{Methods \\ Participants}

The participants in the current study were identified from the larger Robot for Autism Behavioral Intervention project (RABl; So et al., 2020), an intervention conducted at The Chinese University of Hong Kong for (Cantonese) Chinese-speaking individuals with autism aged three to 18 years. A subset of these participants $(N=37 ; 32$ males) contributed language samples over a nine-month intervention. On average, they were aged between five and six years $(S D=$ 10.46 months; ranging from 49 to 100 months). Data were collected at The Chinese University of Hong Kong.

All children participating in the study had been diagnosed with autism between the ages of 18 and 36 months $(M=27.24 ; S D=5.12)$ by pediatricians at the Child Assessment Centre for the Department of Health in Hong Kong. Their ASD diagnoses were further confirmed by the research team using the Autism Diagnostic Observation Schedule-Second Edition (ADOS-2; Lord et al., 2012) and by pediatricians from the Pamela Youde Child Assessment Centre, Hong Kong, who used the fifth edition of the Diagnostic and Statistical Manual of Mental Disorders (DSM-5; APA, 2013). All the children met the ADOS-2 and DSM-5 criteria for ASD. They were attending either a special care center or a mainstream kindergarten in Hong Kong at the time of the present study.

All the procedures were approved by the institutional review board of the first author's university, in compliance with the Declaration of Helsinki (Survey and Behavioral Research Ethics Reference No. SBRE-19-307). We obtained the parents' informed consent prior to the start of the study. The children also gave their verbal consent to participation, which was required for children of this age by the institutional review board of the university.

\section{Assessments}

Autism Diagnostic Observation Schedule-Second Edition (ADOS-2). The ADOS-2 assesses and diagnoses ASD across age, developmental level, and language skills (Lord et al., 2012). In the present study, it was conducted by a trained professional who had completed ADOS-2 Advanced/Research Training. ADOS comparison scores converted from the total raw scores according to the age of the children are reported here.

Childhood Autism Rating Scale ${ }^{\text {TM }}$-Second Edition (CARS ${ }^{\mathrm{TM}}-2$ ). The CARS-2 helps to identify children with autism and to determine symptom severity through quantifiable ratings based on direct observation (Schopler, Van Bourgondien, Wellman, \& Love, 2010). Children's standardized scores are reported.

Social Responsiveness Scale-Second Edition (SRS-2). Caregivers of the participating children were invited to take the SRS-2; Constantino, 2012). The SRS-2 has 65 questions scored 0 to 3 on a Likert-type scale, which identifies the severity of social impairment in individuals with ASD. Children's total scores on the SRS-2 are reported.

Kaufman Brief Intelligence Test-Second Edition (KBIT-2). The KBIT-2 assesses both verbal and nonverbal intelligence in people from four through 90 years of age (Kaufman, 2004). It is composed of two separate scales: the Verbal Scale contains two kinds of items-verbal knowledge and riddles-both of which assess crystallized ability (knowledge of words and their meanings); the Nonverbal Scale includes a matrices subtest that assesses fluid thinking-the ability to solve new problems by perceiving relationships and completing analogies. Test items are free of cultural and gender bias. Children's standardized verbal and nonverbal scores, plus a composite IQ, are reported.

Mullen Scales of Early Learning (MSEL). The MSEL measures children's abilities in four cognitive domains: visual reception, fine motor skills, receptive language, and expressive language (Mullen, 1995). We focused on receptive and expressive language skills and reported children's equivalent age language scores.

Table 1 shows the descriptive statistics of age and performance in various assessment tasks. All the children but one had an ADOS score equal to or greater than the cutoff point and were thus confirmed to have ASD. The child with an ADOS score lower than the cutoff point was not excluded as he had been diagnosed with ASD when he was two and the findings were the same after including his data. All the children had high cognitive functioning (total IQ 100) but most had delayed expressive and receptive language abilities. 
Table 1

Descriptive statistics of age and assessments

\begin{tabular}{|llllll|}
\hline Measures & & Mean & SD & Median & Range \\
\hline Age & & 66.14 & 10.46 & 66 & $49-100$ \\
& Social affect & 8.76 & 4.68 & 9 & $1-20$ \\
& Restrictive and repetitive behavior & 2.05 & 1.91 & 2 & $0-6$ \\
\hline CARS & comparison score & 5.51 & 2.8 & 6 & $1-10$ \\
\hline SRS & & 29.05 & 3.86 & 28.72 & $21.1-35.47$ \\
\hline \multirow{2}{*}{ MSEL } & Receptive language & 90.49 & 26.79 & 90 & $41-156$ \\
& Expressive language & & & & \\
\hline KBIT & Verbal & 52.76 & 10.39 & 55 & $30-69$ \\
\hline & Nonverbal & 43.89 & 8.6 & 43 & $31-67$ \\
& Total & 97.68 & 23.82 & 102 & $33-142$ \\
\hline
\end{tabular}

Notes: ADOS = Autism Diagnostic Observation Schedule; CARS = Childhood Autism Rating Scale; SRS = Social Responsiveness Scale; MSEL = Mullen Scales of Early Learning Scale; KBIT = Kaufman Brief Intelligence Test $-2^{\text {nd }}$ Edition.

\section{Parent-child Interaction}

Parents were invited to interact with their children for 20 minutes in a treatment room at four time points. Each time, the child was presented with a standardized set of age-appropriate toys and their parent was instructed to play with the child as they normally would at home. All participating children and their parents played with the same set of toys at each time point; however, the toy sets were different across the four time points. Each session was videorecorded using two cameras with high-definition zoom-in functions to capture the head and hand movements of parent and child.

Transcriptions. The language samples were transcribed by research assistants trained in the Codes for the Human Analysis of Transcripts (CHAT) format using Computerized Language Analysis (CLAN) software (MacWhinney, 2000). Each language sample was transcribed verbatim by one transcriber, who viewed each recording multiple times until the entire sample was transcribed. Following CHAT coding conventions, utterances or portions of utterances that could not be fully transcribed after three viewings were indicated as unintelligible. A consensus procedure was implemented: the transcribers viewed each other's video recordings while reading the initial transcriptions (Shriberg, Kwiatkowski, \& Hoffmann, 1984). When errors or discrepancies were discovered, the transcribers discussed among themselves until agreement was reached. Otherwise, those utterances or portions of utterances were considered unintelligible.

Coding. We first identified the conversation topic of each utterance. Topic was defined by the referent object and ongoing actions for events (Yoder \& Davies, 1990). Parents and children played with standardized toy sets, such as police figurines, puzzles, a cash register, and model dinosaurs, which were placed on the table. They mainly conversed about these toys during interactions. Utterances that were not related to these toys were excluded from further coding. Utterances that were unintelligible were also removed. We report here the number of conversation topics in each parent-child dyad.

For each conversation topic, we identified parents' verbal responsiveness and redirectives based on the coding system established in the studies by Yoder and colleagues (Yoder \& Davies, 1990; Yoder, Davies, \& Bishop, 1994). Parents' utterances were coded as verbal responsiveness when these utterances (either in the form of questions or non-questions) had the same or related topic to the preceding utterances, assuming that the non-initiating partner had talked about the topic at least once in that exchange. Utterances were coded as redirectives when their topic was unrelated to that of the preceding utterance or when these utterances were about a topic that the non-initiating partner had not yet talked about during the conversation. We calculated the proportions of verbal responsiveness and redirectives.

Similarly, children's utterances were coded as responses or initiation of conversation. Children's utterances were coded as responses if they were responding to their parents' preceding utterances. We examined whether these responses were appropriate in a conversation. A response was considered appropriate when it was relevant to the conversation topics either verbally or nonverbally. Examples of appropriate response were asking a follow-up question (e.g., "How much does it cost?" when playing with a toy cash register), showing understanding or agreement with the previous utterance (e.g., "ok" or nodding), and sharing/giving qualifying and relevant information (e.g., "This dinosaur can fly! Look at me!"). Examples of inappropriate responses were echolalia (i.e., repetition of what has just been said), idiosyncratic speech (e.g., singing a song when asked, "What is it?"), and sharing/giving inadequate and irrelevant information (e.g., saying, "One, two, three, four" while pointing to the dinosaurs in response to the question, "Where is the dinosaur?"). Responses were coded as nil if the child did not respond and the parent prompted him/her. We calculated the proportion of children's appropriate responses, that is, the number of utterances showing children's appropriate responses divided by the total number of utterances. Children's utterances were coded as initiation of conversation if their topics were unrelated to the preceding utterances. 
We also counted the number of conversational turns taken by parent and child in each conversation topic. A conversational turn was counted in pairs: one utterance by adult/child and then one by child/adult in response, with the second utterance being contingent upon the first. For example, if a child spoke and his/her parent responded, or vice versa, that would count as one turn. If the child responded to the adult on the same conversation topic, and the parent responded again, that was considered two conversational turns.

We established the reliability of our measures by asking a second individual to transcribe $20 \%$ of the videotaped sessions. Agreement between the coders was $93.87 \%$ for the identification of conversation topics (Cohen's Kappa $=.91, p<.001$ ), $99.85 \%$ for the identification of the initiator of the conversation (Cohen's Kappa $=.98, p<.001)$, and $87.32 \%$ for the identification of the appropriateness of response (Cohen's Kappa $=.85, p<.001)$.

\section{Results}

Overall, there were a total of 2,368 conversation topics with 987 conversational turns across 37 children over four time points. On average, each parent-child dyad had 15.38 conversation topics $(S D=5.28$; ranging from 10.73 to 19.59$)$ and 2.23 conversational turns for each topic $(S D=.72$; ranging from 1.77 to 3.31). Altogether there were 4,461 utterances; of which $63 \%$ contributed by the parents $(N=2,810)$ and the rest by their children $(N=1,651)$. Of the utterances produced by the parents, $67.37 \%$ were coded as verbal responsiveness and the remaining were redirectives. Of the utterances produced by the children, $65.88 \%$ were responding to their parents while the rest were initiation of conversation. We first examined whether there was growth in the children's conversation skills (appropriate responses, maintenance of conversation, and initiation of conversation) over nine months, followed by the association of parents' verbal responsiveness and redirectives and children's appropriate responses.

\section{Growth Of Conversational Skills}

Figure 1 shows the changes of different conversational skills across the children at four time points while Fig. 2 plots the growth of different conversation skills for each child over the same time period.

Separate hierarchical linear modeling (HLM) analyses were conducted to model the growth curve trajectories for different conversation skills (Garson, 2013). For each ability, we first fit the data to a null model to test whether there was significant variation across individuals, and if so, we fit the data using two unconditional growth models: (i) a random intercept model measuring the overall fixed effect for time across all children given their different initial levels of the target outcome; and (ii) a random intercept and slope model measuring the overall fixed effect for time and examining whether the slope of the time effect varied across children. Log likelihood and Chi-squared test were also used to determine the best model fit. Data analyses were conducted by R (version 3.6.1) using the "Ime4" package.

We first fit an HLM with the proportion of appropriate responses as the outcome variable (Table 2). There was significant variation in the proportion of appropriate responses across the children $(\beta=.35, S E<.01)$. Time as the fixed effect was then entered into the random intercept model and the random intercept and slope model. The results show that the time effect was not significant, suggesting that the improvement in the appropriate responses over time was not evident.

Table 2

Hierarchical linear modeling analyses for the proportion of appropriate responses by children with autism

\begin{tabular}{|c|c|c|c|c|}
\hline & & Null Model & Unconditional Growth Models & \\
\hline \multicolumn{2}{|l|}{$\begin{array}{l}\text { Appropriate } \\
\text { Response }\end{array}$} & & Random Intercept Model (Model A) & Random Intercept and Slope Model (Model B) \\
\hline \multirow[t]{3}{*}{ Fixed Effects } & & $\beta(S E)$ & $\beta(S E)$ & $\beta(S E)$ \\
\hline & Intercept & $0.35^{\star \star \star}(0.01)$ & $0.34^{\star \star \star}(0.02)$ & $0.34 * \star *(0.02)$ \\
\hline & Time & / & $0.01(0.01)$ & $0.01(0.01)$ \\
\hline \multirow[t]{4}{*}{ Random Effects } & & $\sigma^{2}(S D)$ & $\sigma^{2}(S D)$ & $\sigma^{2}(S D)$ \\
\hline & $\begin{array}{l}\text { Between-person } \\
\text { variance }\end{array}$ & 0.006 & 0.006 & 0.0088 \\
\hline & Time variance & / & / & 0.0003 \\
\hline & Residual variance & $0.0061(0.08)$ & $0.0061(0.08)$ & $0.0056(0.07)$ \\
\hline \multirow[t]{3}{*}{ Model Comparisons } & $\mathrm{ICC}^{\mathrm{a}}$ & 0.51 & 0.51 & 0.61 \\
\hline & Log likelihood & 136.8 & 137.3 & 138.1 \\
\hline & \multicolumn{4}{|c|}{$\begin{array}{l}\text { Null Model vs. Model A: } \chi^{2}(1)=0.99, p=0.32 ; \text { Model A vs. Model B: } \chi^{2}(2)=1.65 p=0.44 ; \\
\text { Null Model vs. Model B: } \chi^{2}(3)=2.65, p=0.45\end{array}$} \\
\hline
\end{tabular}

Note: ICC = Intra-class correlation coefficient.

We next turned to the maintenance of conversation, that is, the number of conversational turns, as the outcome variable (Table 3 ). There was significant variation in the number of conversational turns across the children $(\beta=2.03, S E=.11)$. The time effect of conversational turns was significant $(\beta=.15, S E$ 
Before examining the effects of parents' verbal responsiveness and redirectives, we first determined the variables (autism severity, language abilities, cognitive functioning) that should be controlled for in the random intercept models. Table 5 shows the correlation among children's different conversation skills, their autism severity and language and cognitive abilities, and their parents' responsiveness. The results show that autism severity assessed by the ADOS, language abilities measured by the MSEL, and cognitive functioning measured by the KBIT-2 correlated with some of the children's conversation skills and parents' responses. Therefore, we entered the ADOS comparison score and the MSEL expressive age equivalent language score into the random intercept models.

Table 5

Correlation coefficients among variables

\begin{tabular}{|c|c|c|c|c|c|c|c|c|c|c|}
\hline & KBIT & ADOS & MSEL_EL & MSEL_RL & $\begin{array}{l}\text { Conversation } \\
\text { tums }\end{array}$ & $\begin{array}{l}\text { Children } \\
\text { appropriate } \\
\text { responses }\end{array}$ & $\begin{array}{l}\text { Children } \\
\text { inappropriate } \\
\text { responses }\end{array}$ & $\begin{array}{l}\text { Children } \\
\text { NIL } \\
\text { responses }\end{array}$ & $\begin{array}{l}\text { Parents' verbal } \\
\text { responsiveness }\end{array}$ & $\begin{array}{l}\text { Parents' } \\
\text { redirectiv }\end{array}$ \\
\hline KBIT & - & $-0.34^{\star}$ & $0.521^{\star \star}$ & $0.523^{\star *}$ & 0.021 & 0.119 & $-0.318^{*}$ & 0.005 & 0.305 & 0.178 \\
\hline ADOS & $-0.34^{*}$ & - & -0.295 & -0.2 & 0.129 & -0.004 & 0.285 & -0.119 & $-0.315^{\star}$ & -0.279 \\
\hline MSEL_EL & $0.521^{\star \star}$ & -0.295 & - & $0.72^{\star \star \star}$ & -0.105 & -0.047 & -0.047 & 0.072 & -0.03 & 0.016 \\
\hline MSEL_RL & $0.523^{\star \star}$ & -0.2 & $0.72^{\star \star \star}$ & - & -0.03 & -0.009 & -0.216 & 0.103 & 0.05 & 0.106 \\
\hline $\begin{array}{l}\text { Conversation } \\
\text { turns }\end{array}$ & 0.021 & 0.129 & -0.105 & -0.03 & - & $0.91^{\star \star \star}$ & $-0.453^{\star \star}$ & $-0.81^{\star \star \star}$ & 0.249 & $-0.705^{\star \star \star}$ \\
\hline $\begin{array}{l}\text { Children } \\
\text { appropriate } \\
\text { responses }\end{array}$ & 0.119 & -0.004 & -0.047 & -0.009 & 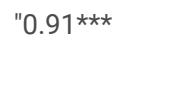 & - & $-0.426^{* *}$ & $-0.921^{\star \star \star}$ & $0.467^{\star \star}$ & $-0.542^{\star * \star \star}$ \\
\hline $\begin{array}{l}\text { Children } \\
\text { inappropriate } \\
\text { responses }\end{array}$ & $-0.318^{*}$ & 0.285 & -0.047 & -0.216 & $-0.453^{\star \star}$ & -0.426 ** & - & 0.04 & $-0.701^{\star \star \star *}$ & -0.133 \\
\hline $\begin{array}{l}\text { Children NIL } \\
\text { responses }\end{array}$ & 0.005 & -0.119 & 0.072 & 0.103 & $-0.81^{\star \star \star}$ & $-0.921^{\star \star \star}$ & 0.04 & - & -0.214 & 0.656 *** \\
\hline $\begin{array}{l}\text { Parents' verbal } \\
\text { responsiveness }\end{array}$ & $0.305^{\star}$ & $-0.315^{\star}$ & -0.03 & 0.05 & 0.249 & $0.467^{\star *}$ & $-0.701^{\star \star \star}$ & -0.214 & - & $0.4^{*}$ \\
\hline $\begin{array}{l}\text { Parents' } \\
\text { redirectiveness }\end{array}$ & 0.178 & -0.279 & 0.016 & 0.106 & $-0.705^{\star \star \star}$ & $-0.542^{\star \star}$ & -0.133 & 0.656 *** & $0.4^{\star}$ & - \\
\hline
\end{tabular}

Notes: Numbers below the diagonal are the unadjusted correlation coefficients and those above the diagonal are the Bonferroni-adjusted correlation coefficients.

ADOS = Autism Diagnostic Observation Schedule; MSEL-EL = Mullen Scales of Early Learning Scale Expressive Language; MSEL: RL = Mullen Scales of Early Learning Scale Receptive Language; KBIT = Kaufman Brief Intelligence Test-2nd Edition.

${ }^{*} p<.05 ; * \star p<.01 ; * \star \star p<.001$

We started by setting the proportion of children's appropriate responses as the outcome variable and parent verbal responsiveness and redirectives as predictors in two separate models (Table 6). In Model 1, we entered parent redirectives manifested in parent-initiated conversation. After controlling for time, the ADOS, and the MSEL, there was a significant negative relationship between the proportion of parents' redirectives and that of children's appropriate responses $(\beta=-.28, S E=.05)$, indicating that the more parents redirect the topics of the conversation, the less likely children were to provide appropriate responses. In Model 2, we added parents' verbal responsiveness and found a significant positive relationship with children's appropriate responses ( $\beta=.25$, SE $=.07$ ), that is, the more parents continued the established conversation topics, the more likely their children were to respond appropriately in the conversation as well. Additionally, Model 2 fit better than Model $1\left(\chi^{2}(1)=13.31, p<0.001\right)$. 
Table 6

Random intercept model with the proportion of children's appropriate responses as the

\begin{tabular}{|c|c|c|c|c|c|}
\hline Predictors & $\beta$ & SE & $95 \% \mathrm{Cl}$ of $\beta$ & $t$ & Pseudo- $R^{2}$ \\
\hline Model 1 & & & & & 0.29 \\
\hline Intercept & $0.57^{\star \star \star}$ & 0.09 & {$[0.39,0.74]$} & 6.64 & \\
\hline Time & -0.00 & 0.01 & {$[-0.02,0.01]$} & -0.82 & \\
\hline MSEL-EL & 0.00 & 0.00 & {$[0.00,0.00]$} & 0.66 & \\
\hline ADOS & $-0.01 \star \star$ & 0.00 & {$[-0.02,0.00]$} & -3.08 & \\
\hline Parents' redirectives & $-0.28 * \star \star$ & 0.05 & {$[-0.39,-0.17]$} & -5.23 & \\
\hline Model 2 & & & & & 0.36 \\
\hline Intercept & $0.43^{\star \star \star}$ & 0.09 & {$[0.25,0.60]$} & 4.83 & \\
\hline Time & 0.00 & 0.01 & {$[-0.01,0.01]$} & 0.02 & \\
\hline MSEL-EL & 0.00 & 0.00 & {$[0.00,0.00]$} & 0.64 & \\
\hline ADOS & $-0.01^{\star \star}$ & 0.00 & {$[-0.02,0.00]$} & -3.04 & \\
\hline Parents' redirectives & $-0.38^{\star \star \star}$ & 0.06 & {$[-0.49,-0.26]$} & -6.61 & \\
\hline Parents' verbal responsiveness & $0.25^{\star \star \star}$ & 0.07 & {$[0.12,0.38]$} & 3.75 & \\
\hline Model Comparisons & Model 1 & Mo & . $x^{2}(1)-1$ & 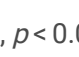 & \\
\hline
\end{tabular}

Notes: MSEL-EL = Mullen Scale of Early Learning-Expressive Language; ADOS = Autism Diagnostic Observation Schedule.

We next set the number of conversational turns as the outcome variable (Table 7). We first entered the ADOS, the MSEL, and parents' redirectives into Model 1. The proportion of parents' redirectives was found to have a negative relationship with the number of conversational turns $(\beta=.51, S E=.11)$. We then entered the proportion of parents' verbal responsiveness into Model 2, which was not found to be significant.

Table 7

Random intercept model with the number of conversational turns as the outcome variable

\begin{tabular}{|c|c|c|c|c|c|}
\hline Predictors & $\beta$ & SE & $95 \% \mathrm{Cl}$ of $\beta$ & $t$ & Pseudo- $R^{2}$ \\
\hline Model 1 & & & & & 0.31 \\
\hline Intercept & $3.59 * \star \star$ & 0.65 & {$[2.28,4.87]$} & 5.55 & \\
\hline Time & 0.04 & 0.05 & {$[-0.06,0.14]$} & 0.80 & \\
\hline MSEL_EL & 0.01 & 0.01 & {$[-0.01,0.03]$} & 1.15 & \\
\hline ADOS & -0.05 & 0.03 & {$[-0.11,0.01]$} & -1.57 & \\
\hline Parents' redirectives & $-2.83^{\star * *}$ & 0.45 & {$[-3.74,-1.92]$} & -6.24 & \\
\hline Model 2 & & & & & 0.32 \\
\hline Intercept & $3.08 * \star \star$ & 0.72 & {$[1.62,4.51]$} & 4.26 & \\
\hline Time & 0.06 & 0.05 & {$[-0.04,0.16]$} & 1.12 & \\
\hline MSEL_EL & 0.01 & 0.01 & {$[-0.01,0.03]$} & 1.13 & \\
\hline ADOS & -0.04 & 0.03 & {$[-0.10,0.02]$} & -1.44 & \\
\hline Parents' redirectives & $-3.16 * * *$ & 0.50 & {$[-4.17,-2.16]$} & -6.32 & \\
\hline Parents' Verbal Responsiveness & 0.89 & 0.58 & {$[-0.26,2.04]$} & 1.52 & \\
\hline Model Comparisons & Model $1 \mathrm{v}$ & Mod & $2: \chi^{2}(1)=2.3$ & $p=0.123$ & \\
\hline
\end{tabular}

Notes: MSEL-EL = Mullen Scale of Early Learning-Expressive Language; ADOS = Autism Diagnostic Observation Schedule.

\section{Discussion}

This study is the first to investigate the conversation abilities in (Cantonese) Chinese-speaking children with autism. It reveals two major findings: (i) some aspects of conversation skills may grow over time in Chinese-speaking children with autism; and (ii) parents' verbal responsiveness, not redirectives, is positively related to their children's production of appropriate responses. 
Few studies have examined social communication and language skills in Chinese-speaking children with ASD. So and colleagues found that school-aged (Cantonese) Chinese-speaking children with ASD gesture less often and use fewer types of gestures, especially markers, in comparison to age-matched peers with typical development, and have difficulty producing iconic gestures to identify referents (So, Lui, \& Yip, 2015; So \& Wong, 2018). Su and colleagues studied expressive language development in a sample of 160 17- to 84-month-old (Mandarin) Chinese-speaking preschoolers with ASD (Su, Naigles, \& Su, 2018). Parents completed the Putonghua Communicative Development Inventory-Toddler form. Three subgroups (low verbal, middle verbal, and high verbal) were defined based on total vocabulary production. The three subgroups displayed discrepancies in lexical components (e.g., the proportion and total utterance of nouns, verbs, and pronouns), syntax, and MLU. Nevertheless, to date, no research has examined the conversation skills of Chinese-speaking children with ASD and their changes over time. Documenting the changes of conversation skills in Chinese-speaking children and their relation to parents' verbal responsiveness and redirectives is critical for designing early intervention.

The first objective of the present study was to model the changes of conversation skills in (Cantonese) Chinese-speaking children with autism aged four to eight years at four time points over nine months. All the children had high cognitive functioning but delayed expressive and receptive language skills. Naturalistic language samples were collected from interactions with their parents, which allowed us to examine their abilities to initiate conversations, provide appropriate responses, and maintain conversations in a social context (DiStefano et al., 2016). We found that there was significant improvement in the proportion of conversation initiated by children (10\%) and the number of conversational turns (from 1.77 turns to 3.31 ) from time point 1 to time point 4 . These results are consistent with those reported in previous studies which found that children with autism made significant improvement in their ability to maintain conversation and in the length and frequency of communication interchanges (DiStefano et al, 2016; Hale \& Tager-Flusberg, 2005). While the improvement of the proportion of appropriate responses was not significant, there is evidence showing a rising trend (from .34 to .37), especially at time point 4 , when the number of conversational turns also drastically increased. We expect that this improvement will be more remarkable later.

The second objective of the study was to find whether parents' verbal responsiveness and redirectives were related to the elicitation of appropriate responses from their children. One of our findings supported the hypothesis that parents' verbal responsiveness positively predicted their children's elicitation of appropriate responses. This result is consistent with previous findings (Yoder \& Davies, 1990; Yoder, Davies, \& Bishop, 1992) that have shown children with developmental delay were more likely to verbally participate in the conversation when their parents continued the children's topic than when they initiated their own topics. Parents' verbal responsiveness scaffolds their children to provide appropriate responses. By continuing the topics that are of children's interest, children find it easier to understand adult speech and be motivated to continue the conversation and respond to their parents appropriately (Yoder et al., 1994). However, our findings did not provide strong evidence showing that parents' verbal responsiveness positively predicted the number of conversation turns.

In contrast, parents' redirectives negatively predicted the children's elicitation of appropriate responses and the number of conversation turns. Some researchers proposed that children with ASD who engage in stereotypic behaviors might need redirectives (i.e., verbal responses that initiate a new topic and require the child to stop attending to the event, object, or person that they are engaged with and attend to something else) to facilitate their interactions with adults (McCathren, Yoder, \& Warren, 1995). However, our findings have shown that parents' redirectives inhibited elicitation of appropriate responses. In comparison to parents' verbal responsiveness, parent redirectives may be more challenging for children with ASD when parents end the current conversation and switch to a different topic. The topic proposed by parents may not interest their children or be familiar to them. Besides, children may prefer conversing on the current topic rather than a new topic proposed by the parent. As a result, parents' redirectives may result in fewer appropriate responses from children in a conversation, thereby reducing the number of conversational turns.

Putting the findings of the parents' verbal responsiveness and redirectives together, we may conclude that continuing the topics that are of children's interest instead of redirecting children's attention to other topics would increase their appropriate responses and help maintain the conversation. Previous research has shown that parents' responsiveness facilitates language development (especially vocabulary use) in children with ASD (McDuffie \& Yoder, 2010; Haebig et al., 2013). Yet, no study to date has examined these children's responses toward their parents' verbal responsiveness and redirectives. The current study fills this gap in the literature. It is possible that, by scaffolding children's participation in a conversation, they are given more opportunities to practice their speech production and gain more inputs from their parents, thereby enhancing their vocabulary and other aspects of language skills.

\section{Limitations}

Though our study is pioneering research into the conversation abilities of Chinese-speaking children with ASD, it has a few limitations. Our language samples were collected from only 37 children. Even though they were followed at four time points, this is too small a sample. Future studies would benefit from larger samples. Additionally, we only included children aged four to eight years, but heterogeneity of language abilities has been observed along the lifespan in individuals with autism (Fountain, Winter, \& Bearman, 2012; Pickles, Anderson, \& Lord, 2014). Besides different age groups, future research should explore both verbal and nonverbal measures of conversation ability (Lord \& Paul, 1997; Young et al., 2005). Finally, research on the verbal responsiveness of parents and its effect on the language acquisition of children with ASD is still in its infancy (Naigles, 2013). More studies should examine the casual relationship between parental inputs and language development.

\section{Conclusions}

To conclude, some aspects of conversation abilities may grow over time in Chinese-speaking children with autism. Parents' verbal responsiveness fosters elicitation of appropriate responses in children with ASD. However, parents' redirectives might make it challenging for children to respond appropriately and even discourage them from maintaining conversations.

\section{Abbreviations}


Autism Diagnostic Observation Schedule - Second Edition (ADOS-2)

American Psychiatric Association (APA)

Autism spectrum disorder (ASD)

Childhood Autism Rating Scale - Second Edition (CARS-2)

Codes for the Human Analysis of Transcripts (CHAT)

Computerized Language Analysis (CLAN)

Diagnostic and Statistical Manual of Mental Disorders, Fifth Edition (DSM-5)

Hierarchical Linear Modeling (HLM)

Kaufman Brief Intelligent Test - Second Edition (KBIT-2)

Mullen Scales of Early Learning (MSEL)

Robot for Autism Behavioral Intervention (RABI)

Social Responsiveness Scale - Second Edition (SRS-2)

\section{Declarations}

Ethics approval and consent to participate: All of the procedures were approved by the Survey and Behavioral Research Ethics Committee of the first author's university, in compliance with the Declaration of Helsinki (SBRE-19-307). We obtained parents' informed consent prior to the study. The participants also gave their assent to participate in this study.

Consent for publication: Not applicable.

Availability of data and materials: The datasets used and/or analyzed during the current study are available from the corresponding author on reasonable request.

Competing interests: The authors declare that they have no competing interests.

Funding: This research has been fully supported by a grant from the Innovation and Technology Fund for Better Living ("FBL”; Project no.

ITB/FBL/8005/17/P).

Authors' contributions: WCSO wrote the manuscript and designed the study. WCSO and XKS analyzed the data. WWL, TW, OKL, and YH collected and coded the data.

Acknowledgements: We acknowledge the help of our research assistants Johnny Fung, Fai-Yeung Kwok, Shing-Hey Lee, Ying-Yi Lee, and Jonathan Tse with data collection and transcription. Special thanks to all of the children and their parents for their help and dedication to education.

\section{References}

1. Adams C, Green J, Gilchrist A, Cox A. Conversational behaviour of children with Asperger syndrome and conduct disorder. J Child Psychol Psychiatry. 2002;43(5):679-90.

2. American Psychiatric A, American Psychiatric Association DSMTF, Joint Information Service of the American Psychiatric A, the National Association for Mental H, American Medico-Psychological A. American Psychiatric Institute for R, et al. Diagnostic and statistical manual of mental disorders: DSM-5. 5th ed ed. Washington, D.C.: American Psychiatric Association; 2013.

3. Baird G, Norbury CF. Social (pragmatic) communication disorders and autism spectrum disorder. Arch Dis Child. 2016;101(8):745-51.

4. Bauminger-Zviely N, Agam-Ben-Artzi G. Young friendship in HFASD and typical development: Friend versus non-friend comparisons. J Autism Dev Disord. 2014;44(7):1733-48.

5. Beals DE. The CHILDES Project: Tools for Analyzing Talk: Vol. 1. Transcription format and programs; Vol. 2. The database. B. MacWhinney. Mahwah, NJ: Erlbaum, 2000. Pp. 366 (Vol. 1); Pp. 418 (Vol. 2). Appl Psycholinguist. 2002;23(2):304.

6. Bloom L, Rocissano L, Hood L. Adult-child discourse: Developmental interaction between information processing and linguistic knowledge. Cognitive Psychol. 1976;8(4):521-52.

7. Bottema-Beutel K, Yoder PJ, Hochman JM, Watson LR. The role of supported joint engagement and parent utterances in language and social communication development in children with autism spectrum disorder. J Autism Dev Disord. 2014;44(9):2162-74.

8. Bottema-Beutel K, Lloyd B, Watson L, Yoder P. Bidirectional influences of caregiver utterances and supported joint engagement in children with and without autism spectrum disorder. Autism Res. 2018;11(5):755-65. 
9. Bottema-Beutel K, Malloy C, Lloyd BP, Louick R, Joffe-Nelson L, Watson LR, et al. Sequential associations between caregiver talk and child play in autism spectrum disorder and typical development. Child Dev. 2018;89(3):e157-e66.

10. Bruner JS. The ontogenesis of speech acts. J Child Lang. 1975;2(1):1-19.

11. Capps L, Kehres J, Sigman M. Conversational abilities among children with autism and children with developmental delays. Autism. 1998;2(4):325-44.

12. Crawley SB, Spiker D. Mother-child interactions involving two-year-olds with Down syndrome: A look at individual differences. Child Dev. 1983:1312-23.

13. Dimitrova N, Özçalışkan Ş, Adamson LB. Parents' translations of child gesture facilitate word learning in children with autism, Down syndrome and typical development. J Autism Dev Disord. 2016;46(1):221-31.

14. DiStefano C, Shih W, Kaiser A, Landa R, Kasari C. Communication growth in minimally verbal children with ASD: The importance of interaction. Autism Res. 2016;9(10):1093-102.

15. Edmunds SR, Kover ST, Stone WL. The relation between parent verbal responsiveness and child communication in young children with or at risk for autism spectrum disorder: A systematic review and meta-analysis. Autism Res. 2019;12(5):715-31.

16. Fountain C, Winter AS, Bearman PS. Six developmental trajectories characterize children with autism. Pediatrics. 2012;129(5):e1112-e20.

17. Garson GD. Hierarchical linear modeling: Guide and applications: Sage; 2013.

18. Haebig E, McDuffie A, Weismer SE. The contribution of two categories of parent verbal responsiveness to later language for toddlers and preschoolers on the autism spectrum. Am J Speech-Lang Pat. 2013.

19. Haebig E, McDuffie A, Weismer SE. Brief report: Parent verbal responsiveness and language development in toddlers on the autism spectrum. J Autism Dev Disord. 2013;43(9):2218-27.

20. Hale CM, Tager-Flusberg H. Social communication in children with autism: The relationship between theory of mind and discourse development. Autism. 2005;9(2):157-78.

21. Harris SS. The relation of maternal style and the language development of children with down syndrome: ProQuest Information \& Learning; 1995.

22. Hoff E, Naigles L. How children use input to acquire a lexicon. Child Dev. 2002;73(2):418-33.

23. Jones CD, Schwartz IS. When asking questions is not enough: An observational study of social communication differences in high functioning children with autism. J Autism Dev Disord. 2009;39(3):432-43.

24. Kasari C, Sigman M. Linking parental perceptions to interactions in young children with autism. J Autism Dev Disord. 1997;27(1):39-57.

25. Lam YG, Yeung SSS. Towards a convergent account of pragmatic language deficits in children with high-functioning autism: Depicting the phenotype using the pragmatic rating scale. Research in Autism Spectrum Disorders. 2012;6(2):792-7.

26. Landa R, Piven J, Wzorek M, Gayle J, Chase G, Folstein S. Social language use in parents of autistic individuals. Psychological medicine. 1992;22(1):24554.

27. Landry SH, Chapieski ML. Joint attention and infant toy exploration: Effects of Down syndrome and prematurity. Child Dev. 1989:103-18.

28. Landry SH, Smith KE, Swank PR, Miller-Loncar CL. Early maternal and child influences on children's later independent cognitive and social functioning Child Dev. 2000;71(2):358-75.

29. Lord C, Rutter M, DiLavore P, Risi S, Gotham K, Bishop S. Autism diagnostic observation schedule-2nd edition (ADOS-2). Los Angeles: Western Psychological Corporation; 2012.

30. Losh M, Capps L. Narrative ability in high-functioning children with autism or Asperger's syndrome. J Autism Dev Disord. 2003;33(3):239-51.

31. McDuffie A, Yoder P. Types of parent verbal responsiveness that predict language in young children with autism spectrum disorder. Language: Journal of Speech; 2010.

32. Naigles LR, editor Input and language development in children with autism. Semin Speech Lang; 2013: Thieme Medical Publishers.

33. Nelson KE. Strategies for first language teaching. 1989.

34. Olsen-Fulero L, Conforti J. Child responsiveness to mother questions of varying type and presentation. J Child Lang. 1983;10(3):495-520.

35. Paul R, Orlovski SM, Marcinko HC, Volkmar F. Conversational behaviors in youth with high-functioning ASD and Asperger syndrome. J Autism Dev Disord. 2009;39(1):115-25.

36. Philofsky A, Fidler DJ, Hepburn S. Pragmatic language profiles of school-age children with autism spectrum disorders and Williams syndrome. Am J Speech-Lang Pat. 2007.

37. Pickles A, Anderson DK, Lord C. Heterogeneity and plasticity in the development of language: A 17-year follow-up of children referred early for possible autism. J Child Psychol Psychiatry. 2014;55(12):1354-62.

38. Schopler E, Van Bourgondien ME, Wellman GJ, Love SR. CARS-2: Childhood Autism Rating Scale-Second Edition. Western Psychological Services Los Angles, CA; 2010.

39. Shriberg LD, Kwiatkowski J, Hoffmann K. A procedure for phonetic transcription by consensus. Journal of Speech Language Hearing Research. 1984;27(3):456-65.

40. Siller M, Sigman M. The behaviors of parents of children with autism predict the subsequent development of their children's communication. J Autism Dev Disord. 2002;32(2):77-89.

41. Siller M, Sigman M. Modeling longitudinal change in the language abilities of children with autism: Parent behaviors and child characteristics as predictors of change. Dev Psychol. 2008;44(6):1691.

42. So W-C, Luk SH, Law WW, Wong T, Less. C. Robot for autism behavioral intervention. The Chinese Univeristy of Hong Kong. 
43. So W-C, Wong K-YM. Tracing the development of spatially modulated gestures in the manual modality in nonsigning Chinese-speaking children. Appl Psycholinguist. 2018;39(3):527-44.

44. So W-C, Wong MK-Y, Lui M, Yip V. The development of co-speech gesture and its semantic integration with speech in 6-to 12-year-old children with autism spectrum disorders. Autism. 2015;19(8):956-68.

45. Tager-Flusberg H, Paul R, Lord C. Language and communication in autism. Handbook of autism and pervasive developmental disorders. 2005;1:335-64.

46. Tager-Flusberg $\mathrm{H}$, Anderson $\mathrm{M}$. The development of contingent discourse ability in autistic children. Journal of child Psychology Psychiatry. 1991;32(7):1123-34.

47. Tomasello M, Farrar MJ. Joint attention and early language. Child Dev. 1986:1454-63.

48. Volden J, Coolican J, Garon N, White J, Bryson S. Brief report: Pragmatic language in autism spectrum disorder: Relationships to measures of ability and disability. J Autism Dev Disord. 2009;39(2):388.

49. Wetherby AM, Watt N, Morgan L, Shumway S. Social communication profiles of children with autism spectrum disorders late in the second year of life. J Autism Dev Disord. 2007;37(5):960-75.

50. Yoder P, Davies B, Bishop K. Getting children with developmental disabilities to talk to adults. Causes and effects in communication and language intervention. 1992:255-76.

51. Yoder PJ, Davies B. Do parental questions and topic continuations elicit replies from developmentally delayed children? A sequential analysis. Journal of Speech Language Hearing Research. 1990;33(3):563-73.

52. Yoder PJ, Davies B, Bishop K, Munson L. Effect of adult continuing wh-questions on conversational participation in children with developmental disabilities. Journal of Speech Language Hearing Research. 1994;37(1):193-204.

53. Yoder PJ, Warren SF. Maternal responsivity mediates the relationship between prelinguistic intentional communication and later language. J Early Intervention. 1999;22(2):126-36.

54. Ninio A, Snow C. Essays in developmental science. Pragmatic development. Westview Press; 1996.

55. Kaufman AS. Kaufman brief intelligence test-second edition (KBIT-2). Circle Pines: American Guidance Service; 2004.

56. Koegel RL, Koegel LK, Frea WD, Smith AE. Emerging Interventions for Children with Autism: Longitudinal and Lifestyle Implications. 1995.

57. Koning C, Magill-Evans J. Social and language skills in adolescent boys with Asperger syndrome. Autism. 2001;5(1):23-36.

\section{Figures}

(a)

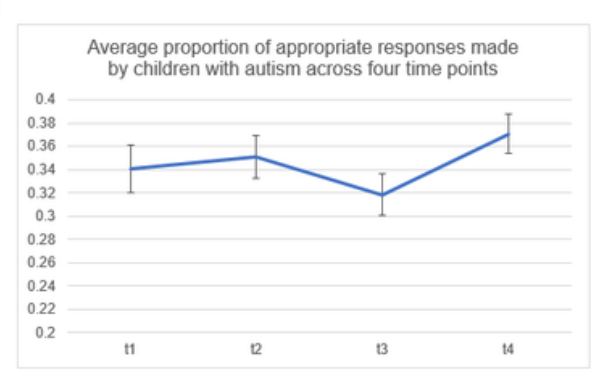

(b)

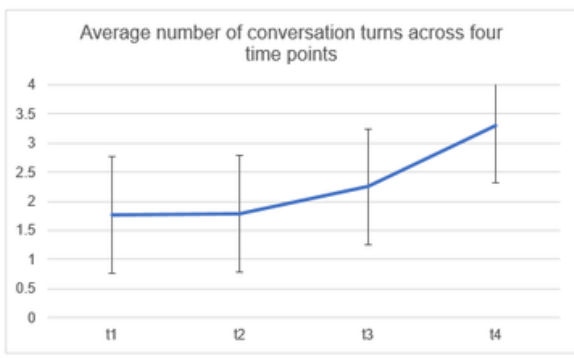

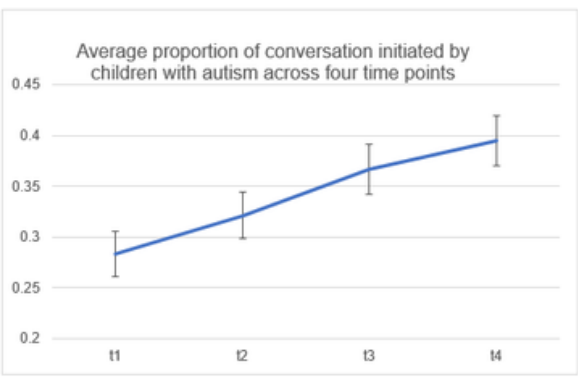

Figure 1

Developmental changes in conversation abilities across children: (a) average proportion of appropriate responses given by children with autism over time; (b) average number of conversational turns over time; and (c) average proportion of conversation initiated by children with autism over time. Notes: The proportion of appropriate responses was calculated as the total number of children's appropriate responses across all conversation topics divided by the total number of children's responses (including children's appropriate responses, inappropriate responses, and nil responses). The proportion of conversation topics initiated by children was calculated as the total number of conversation topics initiated by children divided by the total number of conversation topics initiated by children and parents. 
a.

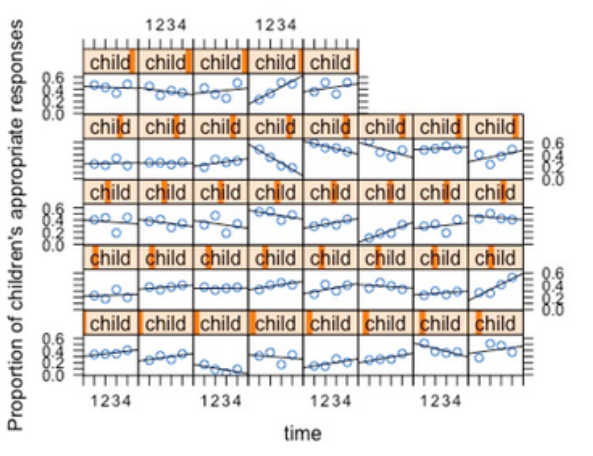

b.

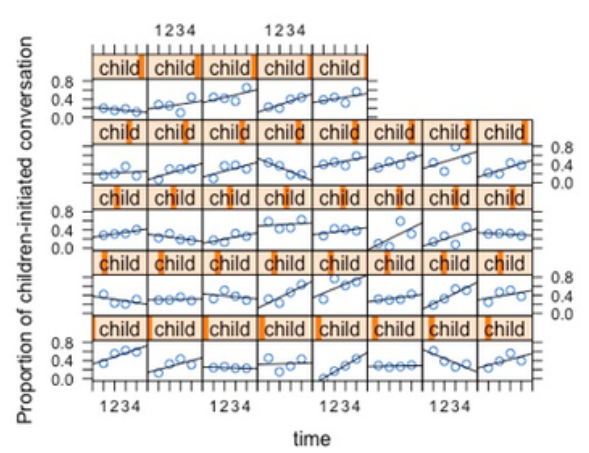

c.

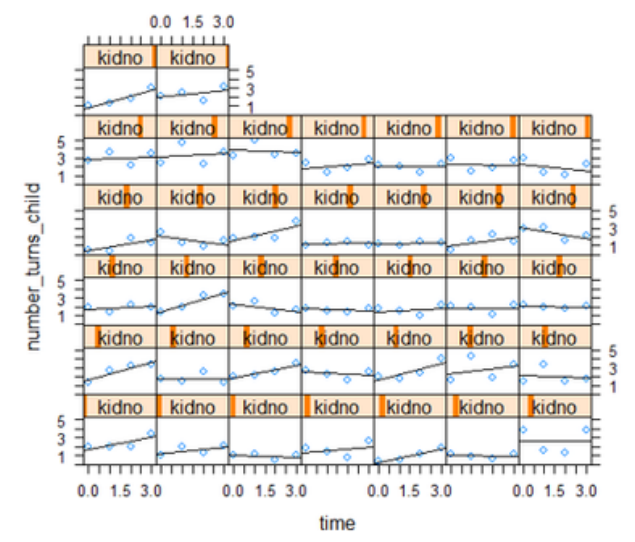

Figure 2

Growth plots of children's conversation abilities: (a) proportion of individual children's appropriate responses; (b) number of conversational turns of individual children; and (c) proportion of conversation topics initiated by individual children. 